\title{
Measurement of Kinetic Friction Coefficient through Magnetic Induction Using Audacity Application in Physics Learning
}

\author{
https://doi.org/10.3991/ijoe.v16i03.12553 \\ Fatkhur Rohman ${ }^{\bowtie}$ ), Yohandri Azwir, Ahmad Fauzan \\ Universitas Negeri Padang, Padang, Indonesia \\ atkhuregmail.com
}

\begin{abstract}
This study was designed to produce an experimental device for measured the coefficient of kinetic friction of material through magnetic induction using Audacity application. The material which is going to be measured is rough acrylic with rough acrylic and wood with rough acrylic. The experimental setup was performed on the motion system of the mass of objects $m_{1}$ and $m_{2}$ that were connected through a pulley on a table and three solenoids are put under a table as the Electromagnetic Field (EMF) sensor. Analysis of the calculation of kinetic friction coefficient used two concepts, i.e. the kinematics concept to identify the load acceleration and the concept of the dynamic to find the kinetic friction coefficient. The results of the measurement of kinetic friction coefficient in this study have a match with the results obtained in the other studies. Hence, the tools and experimental approaches generated in this study are excellent for use in the learning activities so that teachers can teach physics applicatively.
\end{abstract}

Keywords-Kinetic friction coefficient, magnetic induction, audacity, physics learning

\section{Introduction}

Physics studies should be a very interesting study for students to learn in the learning process because the discussion is directly related to natural phenomena that are close to students' daily lives. In fact, many students, however, consider physics to be a difficult subject [1]. This is because in general, physics discusses concepts, equations, and complex topics that make students unable to associate those physical concepts with everyday life phenomena [2-5]. The effort to overcome this problem is to carry out experiments conducted in learning [2]. Carrying out experiments in the classroom or laboratory to study physics, however, is not a solution without problems.

There are many factors that cause the suboptimal of experimental activities in supporting students' understanding of physics. One of the factors is the method of recording data manually which causes the slow process of data collection [6-7], the low level of accuracy of the data obtained, and ineffective use of time. To overcome this issue, new methods such as computer application-based data logging need to be ap- 
plied. The use of computer applications as ICT products allows students to explore and understand the concepts of physics that are in a close relationship with everyday life easier [8]. One of the applications that can be utilized for data logging in physics experiments is Audacity.

Audacity application is Open Source Audio Processor (OSP) software that can be obtained free of charge on the official page. The main function of using Audacity is to record, edit and analyze sound waves [9-13]. The output of the recording using Audacity is in the form of audio files, either .wav, .aiff or .mp3 [9]. Audacity also functions to analyze the frequency of the recorded signal, search for the largest frequency record and record/detect EMF (Electromagnetic Field) signals [14-18]. Many experiments the data of which can be collected using Audacity, such as measuring Earth's gravitational acceleration [14], studying the Doppler effect [10], measuring the speed of sound [13], comparing the effects of factors in electromagnetic induction [15], experimenting resonance tube [11], and so on.

In this study, the discussion focuses on the measurement of the Audacity based kinetic friction coefficient that can be used in learning. Audacity application that can read EMF signals from magnetic induction on solenoid is used as a data logging method for measuring kinetic friction coefficient experiments. The kinetic friction coefficient is analyzed from the data generated by the mass motion system of objects $\mathrm{m} 1$ and $\mathrm{m} 2$ that are connected to each other by a rope through a table pulley. The solenoid is placed below the trajectory of the table, while the mass $\mathrm{m} 1$ that is attached by a magnet moves along the path (Figure 1).

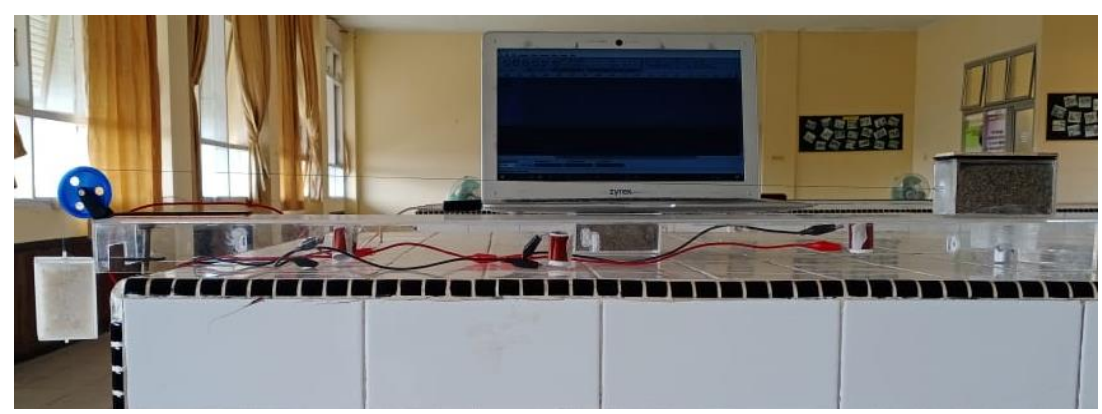

Fig. 1. The experimental setup consists of a trajectory table made of rough acrylic

The equation used in the calculation of the kinetic friction coefficient measurement results in this study is explained in the theory section after this introduction. After that, it will be explained in detail about the experimental setup that is performed when running an experiment. Measurement results and calculations from experimental data are presented and discussed in the results and discussion section. Then in the conclusions section the results of this study were concluded. 


\section{Theory}

The concept of determining the value of the kinetic friction coefficient through magnetic induction can be observed in Fig. 1. There are two systems of object mass $\mathrm{m} 1$ and $\mathrm{m} 2$ that are connected to each other by a rope. The system of mass $\mathrm{m} 1$ is on a path that will move when it receives the force from $\mathrm{m} 2$. The decrease of kinetic friction coefficient equation according to Fig. 1 uses two concepts, which are the concept of kinematics and the concept of dynamics.

\subsection{The concept of kinematic}

The concept of kinematics is used to determine the acceleration (a) that is experienced by the system. The acceleration experienced by the system is assumed to be constant because the force given by mass $\mathrm{m} 2$ does not change. The initial position equation ( $\mathrm{s} 0$ ) with $\mathrm{v} 0=0$ is

$$
s_{0}=v_{0} t+\frac{1}{2} a t^{2}
$$

The equation of position 1 (s1) with $\mathrm{v} 01 \neq 0$ is

$$
\begin{gathered}
v_{01}=v_{0}+a t \quad s_{1}=v_{01} t_{1}+\frac{1}{2} a t_{1}^{2} \\
\frac{s_{1}}{t_{1}}=v_{01}+\frac{1}{2} a t_{1}
\end{gathered}
$$

The equation of position 2 (s2) with $\mathrm{v} 02 \neq 0$ is

$$
\begin{gathered}
v_{02}=v_{01}+a t_{1} \quad s_{2}=v_{02} t_{2}+\frac{1}{2} a t_{2}^{2} \\
\frac{s_{2}}{t_{2}}=\left(v_{01}+a t_{1}\right)+\frac{1}{2} a t_{2}
\end{gathered}
$$

By subtracting equation (3) and (2), the result is

$$
\frac{s_{2}}{t_{2}}-\frac{s_{1}}{t_{1}}=\frac{1}{2} a\left(t_{1}+t_{2}\right)
$$

Therefore, the value of acceleration is determined by the equation of 


$$
a=\frac{2\left(\frac{s_{2}}{t_{2}}-\frac{s_{1}}{t_{1}}\right)}{\left(t_{1}+t_{2}\right)}
$$

The value of a which is influenced by the measurement results of $\mathrm{s} 1, \mathrm{~s} 2, \mathrm{t} 1$, and $\mathrm{t} 2$ causes the error calculation used to be error propagation [19], the value of which is

$$
s_{a}=\sqrt{\left(\frac{\partial a}{\partial s_{1}} s_{s 1}\right)^{2}+\left(\frac{\partial a}{\partial s_{2}} s_{s 2}\right)^{2}+\left(\frac{\partial a}{\partial t_{1}} s_{t 1}\right)^{2}+\left(\frac{\partial a}{\partial t_{2}} s_{t 2}\right)^{2}}
$$

With $s_{a}, s_{s_{1}}, s_{s_{2}}, s_{t_{1}}$ and $s_{t_{2}}$ respectively are the error calculation of the acceleration value of the system of the object mass, error measurement of the 1st distance, error measurement of the 2 nd distance, error measurement of the 1st time and error measurement of the 2 nd time.

\subsection{The concept of dynamics}

The concept of dynamics is used to derive equations in the system of object mass $\mathrm{m} 1$ and $\mathrm{m} 2$ to obtain the equation of kinetic friction coefficient with the assumption that the slippery pulley is perfect.

System of mass $\mathrm{m} 1$

$$
\begin{aligned}
& \sum_{i=1}^{n} F_{i}=m_{1} \cdot a \\
& T_{1}-f_{k}=m_{1} \cdot a \quad\left(f_{k}=\mu_{k} N\right) \\
& T-\mu_{k} N=m_{1} \cdot a
\end{aligned}
$$

System of mass $\mathrm{m} 2$

$$
\begin{aligned}
& \sum_{i=1}^{n} F_{i}=m_{2} \cdot a \\
& w_{2}-T_{2}=m_{2} \cdot a \quad\left(w_{2}=m_{2} g\right) \\
& m_{2} g-m_{2} \cdot a=T
\end{aligned}
$$

From the substitution of equation (6) to equation (7), the kinetic friction coefficient with the following equations obtained.

$$
\mu_{k}=\frac{m_{2} g-\left(m_{2} \cdot a+m_{1} \cdot a\right)}{m_{1} g}
$$


$\mu_{k}$ is the kinetic friction coefficient, $\mathrm{m} 1$ is the object mass of $1(\mathrm{~kg}), \mathrm{m} 2$ is the object mass of $2(\mathrm{~kg})$, a is the acceleration of the object mass system $(\mathrm{m} / \mathrm{s} 2)$, and $\mathrm{g}$ is the acceleration of the Earth's gravity $(\mathrm{g}=10 \mathrm{~m} / \mathrm{s} 2)$

Error calculation of kinetic friction coefficient uses the following equation

$$
s_{\mu k}=\sqrt{\left(\frac{\partial \mu_{k}}{\partial m_{1}} s_{m 1}\right)^{2}+\left(\frac{\partial \mu_{k}}{\partial m_{2}} s_{m 2}\right)^{2}+\left(\frac{\partial \mu_{k}}{\partial a} s_{a}\right)^{2}}
$$

With $S_{\mu k}, s_{m 1}, S_{m 2}$ and $s_{a}$ respectively are the error calculation of kinetic friction coefficient values, error measurement of mass 1 , error measurement of mass 2 , and error calculation of acceleration value.

\section{$3 \quad$ Methods}

The setup of experimental devices for measuring the kinetic friction coefficient through magnetic induction using Audacity application consists of a trajectory table made of rough acrylic with the size of $90 \times 15 \mathrm{~cm}$ (Fig. 1).

Object $\mathrm{m} 1$ which is attached by a magnet is placed on the table of the track. The surface of object $\mathrm{m} 1$ and the surface of the table of the track is made of rough acrylic. Object $\mathrm{m} 1$ also has a wooden surface on the other side to be utilized as a variation in the measurement of the kinetic friction coefficient values between wood and rough acrylic.

The load $\mathrm{m} 1$ is connected to the object $\mathrm{m} 2$ using a rope through a pulley at the end of the table (Fig. 2). At the bottom of the track table, there are three solenoids which function as EMF signal sensors when the object $\mathrm{m} 1$ moves. The distance of solenoids 1 and 2 is s1, while solenoid 2 and 3 are separated by the distance of s2. When mass $\mathrm{m} 1$ and magnet move across the solenoid, it will trigger the emergence of a magnetic field signal (EMF) the time data of which can be recorded by Audacity.

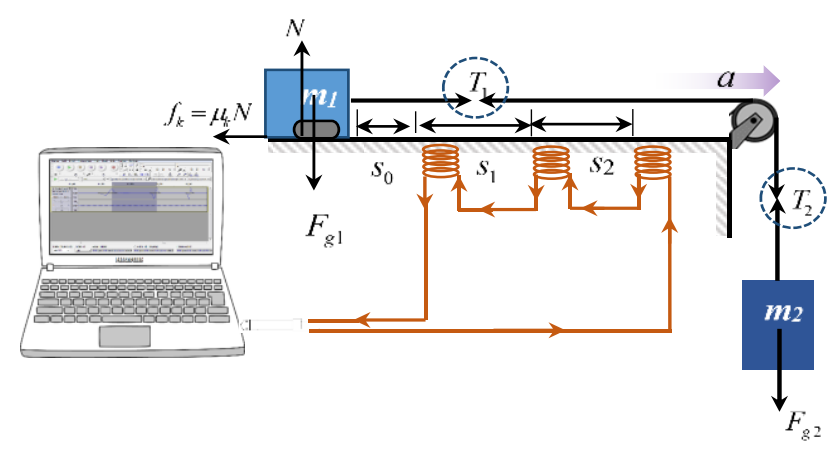

Fig. 2. Free diagram of the motion system in the experiment 
In conducting the experiment, the solenoids are connected in series and at both ends of the circuit are connected to the TS (Tip-Sleeve) audio jack. This type of audio jack has two conductors, one for audio signals and the other for ground. TS audio jack is suitable to be employed in this study because EMF signal input comes from a single channel (mono).

The audio jack is then connected to a USB Sound card. The use of a USB soundcard can overcome the problem of unreadability of the EMF signal which generally occurs when using a laptop with only one audio jack that is stereo and joins the microphone with the speaker. After all the tools and materials are assembled (Fig 2), the retrieval of experimental data to determine the kinetic friction coefficient on the table pulley system can be carried out.

\section{$4 \quad$ Result and Discussion}

In this study, to measure the kinetic friction coefficient, the first thing to do was to determine the acceleration of motion $\mathrm{m} 1$ and $\mathrm{m} 2$ using equation (4). Next, the kinetic friction coefficient was calculated using equation (8). Variables that contributed to equation 4 and 8 were taken repetitively for 20 data retrieval times. The results of the measurement and error calculation data are presented in Table 1.

Table 1. Results of measurements of load mass and the distance between solenoids

\begin{tabular}{|c|c|c|c|c|}
\hline Material object & \multicolumn{2}{|c|}{ Mass (kg) } & \multicolumn{2}{|c|}{ Solenoid distance (m) } \\
\hline \multirow{2}{*}{ Acrylic with acrylic } & $m_{1}$ & $(0.453 \pm 0.004)$ & $s_{1}$ & $(0.402 \pm 0.004)$ \\
\cline { 2 - 5 } & $m_{2}$ & $(0.202 \pm 0.004)$ & $s_{2}$ & $(0.201 \pm 0.003)$ \\
\hline \multirow{2}{*}{ Wood with acrylic } & $m_{1}$ & $(0.479 \pm 0.003)$ & $s_{1}$ & $(0.402 \pm 0.004)$ \\
\cline { 2 - 5 } & $m_{2}$ & $(0.202 \pm 0.004)$ & $s_{2}$ & $(0.201 \pm 0.003)$ \\
\hline
\end{tabular}

After obtaining the measuring results of $\mathrm{m} 1, \mathrm{~m} 2, \mathrm{~s} 1$, and $\mathrm{s} 2$, then the EMF signal data was taken 20 times using Audacity for each friction object of acrylic with acrylic (Fig. 3 left) and wood with acrylic (Fig. 3 right).
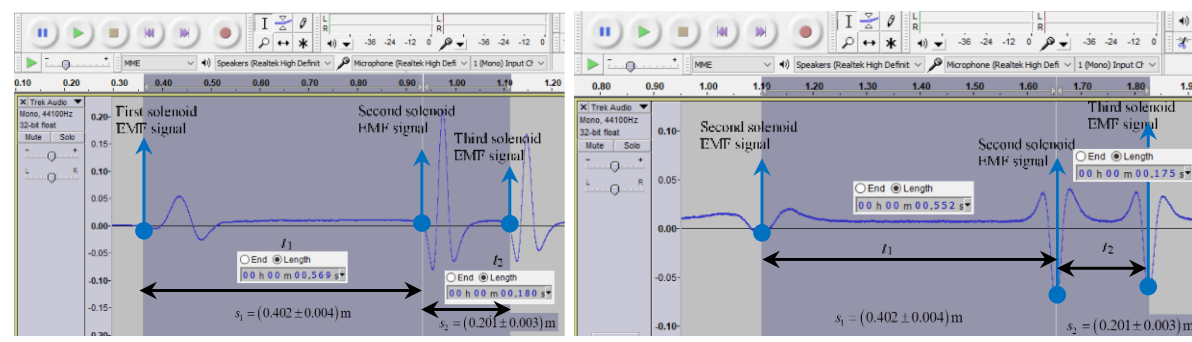

Fig. 3. Display of EMF signals on Audacity output for each friction object of acrylic with acrylic (left) and wood with acrylic (right)

According to the number of solenoids, there were three EMF signals that were captured by Audacity. The three signals were analyzed to obtain time data (Table 2). The 
measurement and EMF sensor response time data when the solenoid was crossed by a magnet in each distance of s1 and s2 were used in the calculation of the acceleration value of the friction object using equation (4).

Table 2. Measurement data from EMF signals

\begin{tabular}{|c|c|c|}
\hline Material object & \multicolumn{2}{|c|}{ Time (s) } \\
\hline \multirow{2}{*}{ Acrylic with acrylic } & $t_{1}$ & $(0.568 \pm 0.002)$ \\
\cline { 2 - 3 } & $t_{2}$ & $(0.183 \pm 0.001)$ \\
\hline \multirow{2}{*}{ Wood with acrylic } & $t_{1}$ & $(0.553 \pm 0.013)$ \\
\cline { 2 - 3 } & $t_{2}$ & $(0.174 \pm 0.005)$ \\
\hline
\end{tabular}

The time required by the friction objects of wood and acrylic in the distance of $\mathrm{s} 1$ and s2 was shorter than the friction objects of acrylic with acrylic. From the results of these measurements, students are going to understand that the acceleration of wood and acrylic friction objects is greater than that of acrylic and acrylic friction objects. Based on the results of calculation with equation (4), the acceleration of wood and acrylic friction object is equal to $(1.185 \pm 0.053) \mathrm{m} / \mathrm{s} 2$. Meanwhile, the acceleration of acrylic with acrylic is equal to $(1.041 \pm 0.048) \mathrm{m} / \mathrm{s} 2$. By substituting the acceleration value into equation (8), the value of the kinetic friction coefficient is determined experimentally and the results are shown in Table 3.

Table 3. Data of the kinetic friction coefficient calculation

\begin{tabular}{|l|c|}
\hline \multicolumn{1}{|c|}{ Material object } & Kinetic friction coefficient \\
\hline Acrylic with acrylic & $(0.296 \pm 0.011)$ \\
\hline Wood with acrylic & $(0.253 \pm 0.011)$ \\
\hline
\end{tabular}

Referring to the results of study by Blau [20], Çoban and Erol [2], Gratton and Defrancesco [21], and Sari [7], the values obtained in this study can be considered as excellent results for the kinetic friction coefficient values for the materials of acrylic with acrylic and wood with acrylic.

\section{Conclusion}

Analysis of the calculation of kinetic friction coefficient used two concepts, i.e. the kinematics concept to identify the load acceleration and the concept of the dynamic to find the kinetic friction coefficient. Referring to the results from other studies, the values obtained in this study can be considered as excellent results for the kinetic friction coefficient values for the materials of acrylic with acrylic and wood with acrylic. The use of Audacity application allows students to explore and understand the concepts of physics that are in a close relationship with everyday life easier. The application of the concept of data logging with this magnetic induction method can be further developed under different conditions, for example measuring the coefficient of kinetic friction on the motion of objects in the incline, on the motion of objects with a pulley system, or by varying various kinds of test material. 


\section{Acknowledgement}

This work was financially supported by the Director General of Research and Development Ministry of Research, Technology, and Higher Education Indonesia through the doctoral dissertation research scheme in 2019-2020. FR acknowledges the support and discussion with Ayu Lusiyana.

\section{$7 \quad$ References}

[1] Baran M. (2016). An Analysis on High School Students' Perception of Physics Course in Term of Gender (A Sample from Turkey). Journal of Education and Training Studies 2016:3. DOI:10.11114/jets.v4i3.1243

[2] Çoban A, Erol M. (2019). Teaching and determination of kinetic friction coefficient using smartphones. Physics Education 2019: 025-019. https://doi.org/10.1088/1361-6552/aaff84

[3] Ekici E. (2016). "Why Do I Slog Through the Physics?" Understanding High School Students' Difficulties in Learning Physics. Journal of Education 2016: 7.

[4] Lusiyana A, Festiyed, Yulkifli. (2019). The problems of integrating multiple representation skills in physics learning. IOP Conference Series: Journal of Physics: Conference Series 1185, 2019: 012-035. https://doi.org/10.1088/1742-6596/1185/1/012035

[5] Ornek F, Robinson W-R, Haugan M-P. (2008). What Makes Physics Difficult. International Journal of Environmental \& Science Education, 2008: 3(1): 30-34.

[6] Liu C, Wu C, Wong W, Lien Y, Chao T. (2017). Scientific modelling with mobile devices in high school physics labs. Computers and Education, 2017: 44-56. https://doi.org/10.10 16/j.compedu.2016.11.004

[7] Sari U. (2019). Using the Arduino for the experimental determination of a friction coefficient by movement on an inclined plane. Physics Education, 2019: 035-010. https://doi. org/10.1088/1361-6552/ab0919

[8] Rohman F, Fauzan A, Yohandri. (2019). Integration of technology in project based learning with tracker on practicum activities. IOP Conference Series: Journal of Physics: Conference Series 1185, 2019: 012-036. https://doi.org/10.1088/1742-6596/1185/1/012036

[9] Asbanu D-E, Babys, Urny. (2017). The Development of Sound Wave Audacity Base Learning Media Using Ethnoscience Approach of Amanuban Tribe to Improve Physics Teacher Candidates' Science Process Skill. International Journal of Science and Research, 2017: 6(11). DOI: 10.21275/28101702

[10] Dias, Marco A, Carvalho, Paulo S, Ventura, Daniel R. (2016). How to study the Doppler Effect with Audacity software. Physics Education, 2016: 51: 035-002. https://doi.org/10.10 $\underline{88 / 0031-9120 / 51 / 3 / 035002}$

[11] Jaafar R, Daud A-N. (2019). Harmonic series experiments in three-in-one resonance tube with audacity software. IOP Conference Series: Journal of Physics: Conference Series 1185, 2019: 012-132. https://doi.org/10.1088/1742-6596/1185/1/012132

[12] Pramudya Y, Widayanti L, Melliagrina F. (2018). Frequency Measurement of BonangBarung and Peking in Javanese Gamelan using Audacity. IOP Conference Series: Journal of Physics: Conference Series 1075, 2018: 012-047. https://doi.org/10.1088/1742$\underline{6596 / 1075 / 1 / 012047}$

[13] Tejedor, Jose A-Gomez, Palacio, Juan C-C, Monsoriu, Juan A. (2014). Direct measurement of the speed of sound by using a microphone and a speaker. Physics Education, 2014: 310-13. https://doi.org/10.1088/0031-9120/49/3/310 
[14] Abellán G, Francisco J, Garcia G, José A, Valerdi P, Ramón P, Ibánez. (2012). Gravity acceleration measurements using a soundcard. European Journal of Physics, 2012: 12711276. https://doi.org/10.1088/0143-0807/33/5/1271

[15] Ismail, Ahmad T, Jaafar R, Daud, Nik S, Ayop S-K. (2016). Quantitative Comparison of The Effect Factors in Electromagnetic Induction Using Audacity Freeware. Proceeding of $3^{\text {rd }}$ International Conference on Research, Implementation and Education of Mathematics and Science, 2016: 16-17.

[16] Muradoglu M, Wei Ng, Enoch M, Wah Ng, Tuck. (2014). Experimentation on recurrent sphere collision with Audacity. European Journal of Physics, 2014: 065-017. https://doi. org/10.1088/0143-0807/35/6/065017

[17] Soares AA, Borcsik FS. (2016). Using a computer microphone port to study circular motion: proposal of a secondary school experiment. Physics Education, 2016: 035-004. https ://doi.org/10.1088/0031-9120/51/3/035004

[18] Soares AA, Reis TO. (2019). Studying Faraday's law of induction with a smartphone and personal computer. Physics Education, 2019: 055-006. https://doi.org/10.1088/1361-6552/ ab26ec

[19] Bevington PR, Robinson DK. (2003). Data Reduction and Error Analysis for the Physical Sciences. New York: McGraw-Hill.

[20] Blau PJ. (2001). The significance and use of the friction coefficient. Tribology International, 2001: 585-91. https://doi.org/10.1016/s0301-679x(01)00050-0.

[21] Gratton LM, Defrancesco S. (2006). A simple measurement of the sliding friction coefficient. Physics Education, 2006: 232-5. https://doi.org/10.1088/0031-9120/41/3/004.

\section{Authors}

Fatkhur Rohman is a student and candidate doctor at Educational Sciences, Doctoral program, Universitas Negeri Padang.

Yohandri is a lecturer in Physics Department, and also Vice Dean at Faculty of Mathematics and Science Universitas Negeri Padang, Indonesia. Yohandri received B.Sc. degree in physics specializing in physics instrumentation from State University of Padang, Indonesia, in 2001 and M.Sc. degree from Bandung Institute of Technology in 2005. The Ph.D degree is obtained in information sciences from Chiba University, Japan, in 2012. Researcher in Center for Environmental Remote Sensing, Chiba University, Japan 2013.

Ahmad Fauzan is a professor of mathematics education and also Head of Doctoral Program at Educational Sciences, Postgraduate Program, Universitas Negeri Padang.

Article submitted 2019-11-29. Resubmitted 2019-12-28. Final acceptance 2019-12-28. Final version published as submitted by the authors 